\title{
«EL REVÉS DE UN AUTÓGRAFO»: NOTAS SOBRE INTIMIDAD E HISTORIA EN ÁNGEL GONZÁLEZ Y LA OTRA SENTIMENTALIDAD
}

\author{
«EL REVÉS DE UN AUTÓGRAFO»: \\ NOTES ABOUT INTIMACY AND \\ HISTORY IN ÁNGEL GONZÁLEZ AND \\ LA OTRA SENTIMENTALIDAD
}

FÉlix Manuel Martín Gijón

Universidad de Granada

RESUMEN: El siguiente trabajo se centra en las relaciones entre intimidad e Historia según el modo en que las teoriza Ángel González en su obra crítica. Estas relaciones pueden dar una clave para entender a Ángel González como referente para los poetas de la otra sentimentalidad.

Palabras Clave: Ángel González; la otra sentimentalidad; historia; intimidad.

Aвstract: The following work focuses on the relations between intimacy and History in the way that Ángel González theorizes them in his critical work. These relations can provide a key to understand Ángel González as a reference for the poets of la otra sentimentalidad.

KEY-WORDs: Ángel González; la otra sentimentalidad; history; intimacy. 


\section{LUGAR COMÚN}

En el muro sombrío de la Historia se ve la huella de una mano ensangrentada. Que la lluvia sea incapaz de borrarla, que el pasado parezca entonces unos graffiti obscenos, es algo que saben los lectores de Ángel González, porque los buenos versos, a menudo, dejan sus huellas sobre la piel del agua y consiguen transformar la mirada ajena en memoria compartida desde la que vivir la propia historia. Los lectores de Ángel González también saben que un poema, a veces, es un muro donde está permitido fijar carteles, tirar escombros, hacer aguas y escribir frases como: Marica el que lo lea, Amo a Irma, Muera el... (silencio), Arena gratis, Asesinos, etcétera. Hay manos que graban mensajes obsesivos de amor, sueños cifrados: los trazos de su caligrafia muestran la obscenidad del tiempo, son como la trayectoria de un cuchillo.

Las imágenes del muro (González, 2009:293, 311,317) no solo tienen el valor de reflexionar sobre el tiempo o el pasado, sino que además aciertan al inscribir la poesía y la historia en la cotidianidad literal del presente; es decir: en la Historia (con mayúscula, como suele escribir Ángel González). Por eso, la espuma sucia de los días empapa el corazón deshabitado de las derrotas, del mismo modo que las heridas íntimas resultan inseparables de los cortes públicos, dejando sus marcas o sus huellas en los muros que sostienen una de esas «mansiones» imprescindibles en «la morada de la poesía» ${ }^{1}$. El poeta ocupa su propio espacio «por fuerza limitado, y desde él piensa, opina y escribe», y al hablar de poesía no está sino «justificando o defendiendo, aunque no lo sepa, su posición dentro de la gran "morada" en la que habita" (González, 2002: 478).Y Ángel González habló sobre Antonio Machado y la dialéctica, sobre el amor y la poesía social, para buscar una tradición de resistencia desde la que dignificar el presente, apostó por una mirada distanciada

1 Es Luis Cernuda quien escribe que «en la morada de la poesía hay muchas mansiones» (García, 2014:214), y González lo recuerda varias veces (1993: 246; 2002: 478). Siguiendo con la imagen, no es dificil advertir que en el "auténtico régimen de extrañamiento» (González, 1991: 253) dominante durante la posguerra, la morada de la poesía - como tantas otras cosas - se encontraba en ruinas; así, los versos de Ángel González: «Atrás quedaron los escombros: humeantes pedazos de tu casa» (2009: 66). En este sentido, se podría comparar a «el derrotado» personaje — también, él mismo, «escombro tenaz» (ibíd.: 15)— que deambula por muchos poemas de Ángel González con otro ángel: el «ángel de la historia», entre las ruinas arrojadas a sus pies (Benjamin, 2008: 310). 
que descree del porvenir para trabajar por el futuro, indagó en los lazos que unen la memoria sentimental y colectiva para levantar los muros de un espacio habitable que abre sus puertas a la duda, al diálogo, a los lectores. Leer, nos dice, «es conversar, compartir el espacio ideal que el verso crea, convivir»(González, 1984: 459). Es sencillo ser huésped en la poesía de Ángel González porque es un poeta que se adelgaza para facilitar la convivencia. Y tiene que ser así, ya que, "por lo que tienen de convivencia, los versos son frecuentemente incómodos, y no toleran lectores indiferentes; o conversos o adversos» (ibíd.) $)^{2}$.

No parece extraño que algunos de esos huéspedes "conversos» y más prolongados sean representantes destacados de la poesía española que se empezó a escribir en la década de los ochenta (Bagué Quílez, 2005; 2014). Lectores atentos, las lecciones de cosas que señala Ángel González han sido demasiado importantes como para no marcar con huellas profundas la obra de muchos de ellos. Si todo poema «es, en cierto modo, un palimpsesto» — como tan machadianamente recordará el mismo González (1987:266)—, elegir las voces que lo pueblan es acogerse a una tradición, donde las huellas que se borran son tan importantes como las que se siguen o las que marcan. Ángeles Mora lo escribe de un modo preciso en «Casa de citas» — juego con doble sentido que, por cierto, también hace González (1987: 270) — al indicar que las voces, «mínimos homenajes», que acompañan a los propios versos, más que «deudas del corazón» o "pura literatura», se explican más sencillamente desde la conciencia de «no borrar nuestras huellas» (Mora, 2001: 69). La poesía de Ángel González, «una continua lección de diferentes cosas» (Salvador, 1995: 93), ha dejado huellas permanentes en los poetas de la otra sentimentalidad. Así lo han detectado los críticos que se ha ocupado de este fenómeno - entre los que, sin exhaustividad, encontramos a Díaz de Castro, 2003: 29; Iravedra, 2010: 30; Rodríguez, 1999: 289; Soria Olmedo, 2000: 125; Wahnón, 2003: 507 - y así lo han admitido los propios autores, a veces metidos a críticos, en numerosos testimonios. Intentar rastrear algunas de estas huellas en sus planteamientos teóricos, abordar la manera en que poetas como Luis García Montero o Álvaro Salvador han leído

2 En esta misma línea, García Montero (2014: 158) se ha referido a la poesía como un «ejercicio de hospitalidad» donde, a la hora de escribir, «hay que saber estar y saber borrarse en el poema». 
en la obra de Ángel González la intimidad y la Historia, el pudor desde el que el yo analiza sus sentimientos sin caer en sentimentalismos, puede resultar un ejercicio de cierto interés.

\section{PALABRAS NUEVAS / PALABRAS OTRAS. EL VIEJO TOPO}

Ángeles Mora nos da unas claves precisas desde las que comenzar el rastreo. La autora de La dama errante (1990) reconoce que, junto a la «sordina romántica» de Gil de Biedma y otras múltiples influencias, la distancia ofrecida por la «ironía» tan sabiamente empleada por González resulta fundamental para consolidar una voz propia que huya del «sentimentalismo» (Mora, 2006: 109). La relación cotidiana entre vida y muerte que Ángeles Mora encuentra en los versos de «Cumpleaños» — con los que abre su citado libro-, «la guerra para mover el corazón todos los días», hace que se pregunte por otra guerra, la de «nuestro mercado cotidiano de la vida»: «¿Quién o qué hace que la vida nos canse y nos deshaga, quién o qué inscribe nuestra vida en los anales de una guerra cotidiana? ¿Quién construye nuestra historia diaria, si solo somos sus heridos?». Bajo estas condiciones, cumplir años es «rebelarse contra una historia que nos roba los días», y, así, la lección fundamental: «Quizá en el poema de Ángel González encontré otra manera de intentar aprehender el mundo, quizá aprendí ahí esa manera condensada de la necesidad de otra historia» (ibíd.: 111). Aprehender el mundo no es lo mismo que interpretarlo; de ahí que "la necesidad de otra historia» a la que se refiere Mora, sea inseparable de la noción de transformación, tal y como aparece en la XI tesis sobre Feuerbach. En el trabajo de transformación las palabras también juegan su papel. Como plantea Luis García Montero en una famosa conferencia, ligando su noción de utilidad - lejos del «utilitarismo» burgués - con las posibilidades de transformación que ofrece la literatura,

[n]ada hay más útil que la literatura, porque ella nos enseña a interpretar la ideología y nos convierte en seres libres al demostrarnos que todo puede ser creado y destruido, que las palabras se ponen una detrás de otra como los días de un calendario, que vivimos, en fin, en un simulacro decisivo, en una realidad edificada, como los humildes poemas o los grandes relatos, que podemos transformarla a nuestro gusto, 
abriendo o cerrando una página, escogiendo el final que más nos convenga (García Montero, 1992: 41).

«Preámbulo a un silencio»-con sus conocidos versos: «y sonrío y me callo porque, en último extremo, / uno tiene conciencia / de la inutilidad de todas las palabras» (González, 2009: 230)— es valorado tiempo después por Ángel González desde la tensión que se establece entre los «actos» y las «palabras», desde la desconfianza «de cualquier intento, por modestos que fuesen sus alcances, de incidir verbalmente en la realidad» (González, 1980a: 412). Mediada la década de los sesenta, la «inmutabilidad» de una dictadura a la que no se veía salida hacía recelar no solo de entender la poesía como arma, sino también de la idea de futuro. La cuestión no deja de tener interés para el Luis García Montero que hace de la «utilidad» una de las señas más destacadas de su poética. El poeta granadino observa que Ángel González, gran conocedor de la obra celayana, siempre se apresuraba a matizar que ni siquiera Celaya consideraba que con un poema se pueda transformar la historia social de un país (García Montero, 2008b: 32). La desconfianza en las palabras no puede reducirse a un debate sobre su utilidad política porque es, además, un cuestionamiento de las relaciones entre el individuo y la sociedad, una interrogación sobre la propia constitución del yo (ibíd.). Sin embargo, frente a las salidas esteticistas o hermetistas con las que se suelen resolver las crisis del lenguaje, la formación ética y estética de Ángel González hizo que se sintiese «más atraído por la escenificación de la duda, la descomposición de la seguridad en la voz o en el punto de vista, la desarticulación de las dignidades poéticas» (ibíd.: 33). A partir de ahí, ya se sabe, esa «segunda» etapa de González. No es extraño que, de un modo casi idéntico al de García Montero, González vuelva a asociar la utilidad de las palabras con la transformación:

Las palabras nunca son inútiles, y eso se debe a la capacidad para iluminar la realidad, para ajustar cuentas con ella. Si las palabras cumplen bien su tarea y están bien elaboradas, pueden iluminar la realidad, y eso implica siempre una transformación del mundo, la sugerencia de que un final puede ser distinto, o de que la historia pasa factura (González / García Montero, 2007: 35). 
Incluso, "aun sin ambiciones de transformar el mundo», solo con la modesta pretensión de clarificarlo o de confundirlo, de nombrarlo o de borrarlo, «la poesía confirma o modifica nuestra percepción de las cosas, lo que equivale, en cierto modo, a confirmar o modificar las cosas mismas» (González, 1980a: 414). En este sentido, no es dificil recordar dos títulos tan significativos como "A veces, un cuerpo puede modificar un nombre» $\mathrm{y}$ «También un nombre puede modificar un cuerpo" (González, 2009: 469, 470). Solo que el concepto de transformación, como veremos, es inseparable del de producción pues, en efecto, «nosotros llegamos unos años después y supimos que casi todo pasaba» por ahí (García, 2002a: 31).

En una crónica espeluznante sobre la posguerra y el régimen de extrañamiento que hizo de los derrotados unos «extranjeros» en su propio país, Ángel González se refiere no a la necesidad de reanudar los vínculos con una tradición rota, sino a la de "crear, allí y entonces, una cultura diferente, o mejor aún disidente respecto a la cultura oficial» (González, 1991: 257). De ello se ocuparon los «exiliados interiores» cuando fueron capaces de pasar «del extrañamiento y la forzosa pasividad a la resistencia y a la oposición» (ibíd.). En ese sentido serían más decisivos Tranquilamente hablando de Celaya y Alegría de Hierro que las obras de un Dámaso Alonso o un Cela, ya que abrieron camino para que en los años cincuenta las cosas fueran distintas. Los cambios de esa época permiten hablar de «un renacimiento de la literatura y, sobre todo, de la afirmación de una literatura disidente, crítica» (ibíd.: 258). Importa señalar la línea que traza González desde los poetas sociales a los del cincuenta porque, de este modo, los hace partícipes de una tarea común, de un proyecto compartido. También importa señalar el plural con el que Ángel González escribe: «Olvidemos / el llanto / y empecemos de nuevo». Observar las cosas es verificar la posibilidad del cambio, la eficacia del tiempo o de la historia: «nada es lo mismo». Y, de ahí, el apremio de los versos finales: «Habrá palabras nuevas para la nueva historia / y es preciso encontrarlas antes de que sea tarde» (González, 2009: 140).

El compromiso con la búsqueda de unas "palabras nuevas» es una tarea colectiva a la que no fueron ajenos los integrantes de la otra sentimentalidad. A finales de los setenta y principios de los ochenta, no se trataba ya de construir una "cultura disidente», de elaborar estrategias de resistencia y lucha frente a un régimen, sino de algo más ambicioso. De alguna manera, esta herencia combativa 
seguía estando presente, pero ahora «más que recordar nuestros sueños en abstracto o más que recordar nuestra historia teníamos que recordar nuestro futuro y tratar de construirlo, al menos en nuestros discursos objetivos» (Rodríguez: 1999: 262). Para ello se necesitaba «una palabra radicalmente histórica» (ibíd.: 270). Si, a pesar de Machado/Mairena, los poetas granadinos hablaron de una «otra sentimentalidad» en lugar de hacerlo sobre una «nueva sentimentalidad», la palabra "radicalmente histórica» no podía ser nueva - como en el poema de González- sino otra, porque el tiempo por el que se trabajaba era un tiempo diferente, una historia otra, lejos de «la disciplina burguesa de la vida» (García Montero, 1983: 15). La distancia ideológica que existe entre las "palabras nuevas» y las "palabras otras» es la misma que se establece entre los maestros del Cincuenta y los poetas de la otra sentimentalidad ${ }^{3}$.

Juan Carlos Rodríguez, en un pequeño cuadernillo de poemas titulado País de amor, explica que el «verdadero compromiso» de la poesía "consiste en ser lo que es: la producción de un artificio o un arte». Lejos de cuestiones técnicas, de mecánica interna del poema, o de simulacros posmodernos, las palabras de Rodríguez nos sitúan en la Historia: un artificio es una "producción histórica» (Rodríguez, 1999: 87), «la poesía es historia, es artificio en sí misma» (ibíd.: 88). El modo en que la poesía se inscribe en la Historia es doble: si por un lado es un «objeto producido por ella», por otro «incide en la historia». Desde esta perspectiva teórica, producción y transformación vuelven a darse la mano: «Si la poesía es artificio y si, en consecuencia, la podemos producir o leer en su propia historicidad (que es la nuestra), quiere decirse con ello que también podemos transformarla. Transformar la poesía o nuestra historia en bloque» (ibíd.: 89). Transformar el mundo — y aquí Rodríguez cita la última tesis sobre Feuerbach - significaría ante todo «la posibilidad de transformar nuestro propio inconsciente», de apostar por «una historia "otra"». La poesía, como forma de vida material, nos señalaría «los límites de nuestras posibilidades de acción, pero también

3 A pesar de ello, Álvaro Salvador no deja de indicar el modo en que, a partir de Sin esperanza, con convencimiento, González «se lanza a la búsqueda decidida de esa "palabra" que le faltaba en su anterior áspero mundo» (1986: 262): una «palabra histórica», ligada a la ironía, el monólogo dramático o el correlato objetivo, que con voluntad «distanciadora» lo aleja del «mesianismo hímnico de sus inmediatos predecesores» a la par que facilita el camino hacia «la elaboración de una voz personal, de un "personaje poético"” (ibíd.: 263). 
el de nuestras ilimitadas posibilidades de transformación» (ibíd.).A pesar de la cuidadosa elaboración teórica de estos planteamientos -o precisamente por eso-, sus resultados casan bien con el Ángel González que hablaba sobre la utilidad de las palabras. Por eso, Juan Carlos Rodríguez termina con un guiño: «Hablar en suma desde el viejo topo de la historia: la única lección de las cosas» (ibíd.: 92) ${ }^{4}$.

\section{INTIMIDAD E HISTORIA}

Ángel González lo dirá de un modo parecido en la antología de Ribes: escribir «desde el centro de la Historia y de acuerdo con su marcha» (1963: 452) .

Álvaro Salvador (1994: 215) explica que la otra sentimentalidad no pretendió ser una escuela, movimiento o grupo, «sino más bien la representación poética de un modo muy concreto de concebir y vivir la

4 Hay otro guiño a Ángel González que no podemos dejar de señalar para situar el proyecto ideológico de la otra sentimentalidad en la conciencia de los límites de su radio de acción. A la "plasmación de una poética de la realidad objetiva", inevitablemente le sigue «su esperanza o, mejor, convencimiento irónico (quieto, apenas un roce) de transformación» (Rodríguez, 1999: 91). Luis García Montero (1987: 207), de un modo similar, duda «que la poesía pueda transformar el mundo, pero desde luego hay poemas que pertenecen de lleno al mundo de la transformación». Tal vez por eso, Jiménez Millán (2003: 190) escribe que la «Historia leída a través de una ciudad, [los] itinerarios sentimentales que intentaban descifrar el presente, aquellos poemas orientados hacia otro romanticismo $[\ldots]$ hablaban, sobre todo, de la posibilidad de una vida menos sórdida».

5 Exactamente dice así: «Escribiendo desde el centro de la Historia y de acuerdo con su marcha, el escritor se quedará, al menos, en la Historia»; y su reverso: «Escribiendo desde la pretendida inmutabilidad de la naturaleza humana, el escritor se quedará probablemente en el olvido» (González, 1963: 452). El planteamiento es similar al que podemos encontrar en Álvaro Salvador: «una poesía que intente reproducir los sentimientos de un modo a-histórico, que intente trasladar los valores sin tener en cuenta el proceso histórico, nunca podrá penetrar el inconsciente colectivo de su época; podrá ser un ilustre y valioso artificio, pero en absoluto tendrá la capacidad de conmover, ni de emocionar, ni de conectar con un público que vive unas muy especiales condiciones de vida, condiciones que no podrán ser recogidas ni resueltas por esa poesía ahistórica. Mairena, como es su costumbre, concluirá esta disertación con una frase lapidaria: Esto debieran aprender los poetas que piensan que les basta sentir para ser eternos» (Salvador, 1983: 21-22). Son apreciables las distancias, por ejemplo, frente a un Juan Ramón que escribe: el poeta «no es nuevo por cantar las novedades, inventos, etc., de una época, que han de estar supuestas en la voz, sino por cantar en cada época, con voz propia, los sentimientos primordiales» (en Cano Ballesta, 1996: 64). 
realidad, $y$ de sentirla»; mientras que Antonio Jiménez Millán (2005: 71) destaca que «si hay un factor que distingue claramente a la propuesta de "la otra sentimentalidad" es la voluntad de no separar literatura, ideología y política». Esta unión era algo que no se le escapaba al Ángel González que, en la antología de Leopoldo de Luis, lúcidamente identificaba las «ideas políticas» con el tema que en realidad se estaba discutiendo al hablar de "poesía social» (González, 1965: 433). Las aparentemente dificiles relaciones que se establecen entre literatura y política se clarifican si ponemos la ideología de lado de la Historia. Es un camino que empieza a atisbar Ángel González cuando dice, con «indudable aire materialista histórico» (García, 2012: 65), que la «[1]a Historia de la poesía, la Historia de la literatura, no es más que un fragmento de la Historia, que siempre es del hombre» (González, 1963: 450) o que «la literatura forma parte de la Historia, es Historia ella misma» (1977:303). Repasar las poéticas que González dejó en algunas de las antologías más importantes de poesía social es constatar la fidelidad y coherencia de un proceso intelectual que se extiende en el tiempo. A la altura del año 68, en la antología de Batlló, destaca esa "profesión de fe en lo social», que mantiene González, «en sus implicaciones "poéticas y extrapoéticas", sobre todo en un momento en que ya era visto como una cosa del pasado» (García, 2012: 67). Aquí encontramos afirmaciones tan decisivas como estas:

No me interesa expresar ese yo ideal en el que algunos todavía creen, encerrado en los insalvables límites de la piel de cada uno: entre otras razones, porque ese yo no existe. Cuando digo expresarme, me refiero a toda mi historia, que es una parte de la Historia que vivimos todos. Esa parte, común, colectiva, es la que determina, incluso, mis confesiones más personales (González, 1968: 457).

Ya en el 2002 escribe un «alegato» - recordemos que su poética del año 65 para la antología de Leopoldo de Luis se tituló «Defensa de la poesía social»— en el que sigue justificando la estética del socialrealismo y del compromiso, a la par que vuelve a incidir sobre lo personal y lo colectivo. Se trata de un lugar privilegiado que condensa muchas ideas de González acerca de la poesía y la Historia, pero donde también se hacen patentes las tensiones ideológicas que puede haber en sus planteamientos. Comienza constatando que las «relaciones de la poesía y la historia» provocan 
«el rechazo de los puristas que creen que la poesía lírica solo debe exponer el mundo íntimo del poeta»; sin embargo, «todo lo que sentimos en nuestro interior, lo que juzgamos más intransferible y puro, más "nuestro", está provocado por algo que existe fuera de nosotros» (González, 2002: 479). Define la «intimidad» como «la huella, o la herida que deja en nuestro espíritu la realidad que contemplamos y vivimos». De este modo, la Historia —entendida como el «conjunto de acontecimientos públicos que nos afectan en mayor o menor medida a todos»— pasa inevitablemente a la vida del hombre; aunque este es un hecho que admite "ciertas gradaciones» (ibíd.: 480). Existen periodos que podrían calificarse más o menos como «normales», durante los que «los ciudadanos pueden vivir relativamente al margen de la historia, enclaustrarse en su mundo privado sin excesivo esfuerzo ni notoria indignidad» (ibíd.). Frente a ello, hay «momentos excepcionales en los que la supuesta normalidad hace quiebra». Lo que ocurre en el entorno inmediato

es tan grave y perturbador que llega a invadir nuestra privacidad, la colma, la nutre. El ser humano cobra entonces conciencia de que es, lo quiera o no, parte de la historia y, como fragmento de un todo que lo desborda, vive enajenado, pierde libertad y opciones: su existencia queda determinada en gran parte por la historia, que condiciona en desproporcionada medida sus actos, su sentimiento, su pensamiento, una importante zona de su ser; y también, si es poeta, de su escritura (ibíd.: 481).

Para González, «el poema nace de todos los estímulos que vienen dados al poeta desde fuera» (1963: 452), y ese «fuera» fue para él la vivencia de las tensiones que la República puso de manifiesto, la revolución asturiana del 34, la guerra civil y la posguerra; todo dentro de una familia muy politizada y «desde el lado de los que perdieron todas las batallas»: «aunque lo hubiese intentado, yo nunca hubiese podido recluirme en una torre de marfil, entre otras razones porque no hay torre capaz de resistir la presión de semejantes circunstancias» (1980: 405). De ahí que la «poesía crítica» sea considerada como «la expresión de una actitud moral, de un compromiso respecto a las cosas más graves que suceden en la Historia que, de alguna manera, estamos protagonizando (1963: 451). Aquí se agolpan las mitologías del compromiso entendido como urgencia, como toma de postura del escritor ante unas circunstancias 
históricas tan apremiantes que terminan por invadir la intimidad o el poema. Pero, como escribe Miguel Ángel García, «la Historia siempre determina la escritura, y siempre invade los ámbitos privados, incluso en los periodos de supuesta normalidad» que señalaba González (García, 2006: 30). Por eso, Benjamín Prado dice que la poesía de Ángel González traza círculos, que sus versos pasan constantemente por los temas de la identidad, del compromiso y del amor, «acotando un espacio en el que las respuestas a la Historia están en el centro y las preguntas privadas en los extremos» (Prado, 2008: 59).

Hay, no obstante, otros momentos en que el González que escribe desde el «centro de la Historia» sitúa la interrogación sobre la intimidad o la subjetividad en este mismo centro, porque tan importante es la historia del corazón como poner el corazón en la Historia. Desde el principio, la pregunta por el nombre propio — «Para que yo me llame Ángel González» (2009: 15)— es inseparable de un espacio y un tiempo marcados por la soledad — «Aquí, Madrid, mil novecientos / cincuenta y cuatro: un hombre solo» (ibíd.: 16)- El marxismo —que Ángel González definía como "una forma de entender el mundo", como "una visión muy inteligente del hombre y de la historia» (1990: 434), en cuya órbita de pensamiento seguía en muchos aspectos (ibíd.: 435)—, no separando el espacio privado del público, ha dado grandes resultados a la hora de enfrentarse con la literatura «al concebir la intimidad como un territorio ideológico y al permitir puntos razonables de articulación entre el escritor y los horizontes históricos» (García Montero, 1993d: 18). Un modo de proceder en esta línea adopta Ángel González. Tras volver sobre el «pesimismo» que atraviesa los poemas de la primera parte de Áspero mundo — pesimismo que lo separa de los esquemas del socialrealismo-, el poeta comprende que la «decepción» que hay en ellos «no era consecuencia de una derrota personal, sino de una catástrofe de mayores dimensiones, de toda una derrota colectiva que incluía la mía» (González, 1980a: 408).Y, de este modo, la afirmación radical: "Cuando mis poemas se refieren a la Historia, en el fondo también se refieren a mí mismo» (ibíd.: 407). Esta manera de identificar las catástrofes colectivas con las derrotas íntimas, la subjetividad con la Historia, la forma que tiene de romper con la dicotomía entre lo privado y lo público, es una razón que explica por qué Ángel González se convirtió en un referente inevitable para los poetas granadinos. 
Si «"[h]istorizar" la subjetividad, en efecto, fue la primera clave de la otra sentimentalidad» (García, 2002b: 16), las reflexiones de González no podían pasarse por alto. Luis García Montero declara que «los lectores de mi generación, comprometidos con la historia azarosa de España y con la dignidad de la literatura, encontramos en la obra de Ángel González el ejemplo de una intimidad convertida en testimonio histórico» (2007: 33). Esta "definición histórica de la intimidad", que "quiere solventar las diferencias abismales que tanto la sociología como la historia de la literatura pretenden hacer entre lo privado y lo público, entre el carácter inmaculado del yo y el sistema de la realidad» (1993e: 97), es uno de los aspectos que más aprecia García Montero como lector de Ángel González (ibíd.: 94). No deja de notar la «clara influencia del pensamiento marxista» que puede haber en esta "concepción histórica de la intimidad» (ibíd.: 98): meditar la intimidad "como territorio histórico» al modo de los poetas del Cincuenta es una postura más cercana a la reflexión distanciada de Brecht que a las consignas de un realismo socialista impuesto por decreto (ibíd.: 99). El poeta granadino destaca «la toma de conciencia del insoslayable carácter histórico de su propia intimidad» a través de la cual se produce el «alcance social de los poemas de Ángel González», ya que cuando «intimidad e historia se funden sin las fronteras cortantes que suelen establecerse entre los aspectos privados y públicos», se enriquecen «los posibles cauces de la llamada poesía social, dirigiéndola hacia una voz de análisis crítico, una reflexión sobre los hábitos colectivos y la propia educación sentimental» (ibíd.: 96).

Todos estos rasgos dan entidad al «personaje moral cómplice y tierno» que caracteriza los poemas de González (ibíd.: 94). La complicidad y la ternura ya aparecen cuando Álvaro Salvador definía la «poética del pudor» con la que caracterizaba la poesía de Ángel González; ; el tono sereno con el que el poeta introduce la ironía para vigilar los excesos sentimentales produce

un distanciamiento cómplice en el lector, una sensación de ternura, primera manifestación de lo que se puede definir de distanciamiento que aligera la peligrosa carga sentimental de ciertas actitudes, algo importante para una persona que, como yo, intenta escribir poesía desde sus experiencias conservando un mínimo de pudor». Luis García Montero no deja de señalar tampoco este rasgo en «El pudor de Ángel» (2007). 
como una poética del pudor, pero que también podemos considerar como uno de los primeros rasgos de lo que más tarde habrá de conocerse como la poética de la Generación del 50 (Salvador, 1986: 264).

Para la otra sentimentalidad, la ternura es un «lema que quiere atrapar la trabazón indisoluble entre dos espacios - los sentimientos íntimos y los compromisos revolucionarios - tradicionalmente vistos como antitéticos» (Iravedra, 2010: 30). La lucha desde la ternura significaba oponerse a un tiempo hostil que quiere terminar con ella, como diagnostica González al comienzo de Tratado de urbanismo: "Queda quizá el recurso de andar solo, / de vaciar el alma de ternura / y llenarla de hastío e indiferencia, / en este tiempo hostil, propicio al odio» (González, 2009: 200). Hay mucho de estos versos en el personaje que atraviesa Paseo de los tristes de Javier Egea - «y esta costumbre vieja de andar erguido y solo»—, como también hay una reflexión compartida con las Canciones del amor prohibido de López Pacheco, pero interesa el término «ternura» porque se convierte en una clave capaz de oponerse «frente a la violencia de la explotación, frente a la brutalidad cotidiana de un sistema basado solo en la necesidad de exprimir el valor los demás, de oprimir a los otros» (Rodríguez, 1998: 165). Hablar desde la ternura es visto por Luis García Montero como «una nueva realidad dentro de la literatura solidaria o comprometida» (1987: 197), porque «el poema amoroso siempre sirve para una reflexión generalizada sobre la historia personal y la educación» (ibíd.: 205). De ahí que «la ternura pueda aparecer de pronto como un peligro revolucionario» (ibíd.: 207). Cuando Álvaro Salvador o Luis García Montero señalan la ternura como clave del personaje poético de Ángel González, lo están incluyendo en esta problemática donde la subjetividad, atravesada por la Historia, se convierte en un «campo de batalla» (García Montero, 1987: 197). Por eso, cuando Luis García Montero explica las relaciones entre el yo y la realidad, recurre a la complicidad con un poemario básico de González donde funde la historia personal con la colectiva, los recuerdos y vivencias con una mirada crítica hacia el panorama donde se produjeron, mediante una poesía escrita a partir de la experiencia de lo cotidiano, configurada por la ciudad (González, 1980a: 411); escribe García Montero: «El yo y la realidad. No creo que se trate de la historia de dos ciudades, sino de la especificación de un mismo tratado de urbanismo» (1993b: 10). 


\section{LOS ESPEJOS DE LA TRADICIÓN}

El mismo García Montero declara que «todo escritor se define en su obra por un diálogo abierto, interesado y singular con la tradición" (1999: 15). Se trata de un viaje al pasado para obtener el apoyo que legitime un proyecto poético propio. La búsqueda de una palabra radicalmente histórica, escribir desde ese centro que es el viejo topo de la Historia, conlleva los riesgos de saltar al vacío, pero la tradición puede convertirse en un buen impulso con el que lanzarse. Para iniciar el «examen de la sentimentalidad» era necesaria «otra tradición poética y otro horizonte ideológico» (García Montero, 1993a: 557) que se alejara de las vanguardias históricas para encontrarse con Antonio Machado, cierto Alberti o los poetas del Cincuenta, entre otros. En el caso de la otra sentimentalidad, García Jaramillo — siguiendo al Miguel Ángel García que explica, no el intento de una «nueva poesía como tal» en los poetas granadinos, sino de «una nueva práctica poética, un desplazamiento en el interior de tal discurso", como Brecht en el teatro y Althusser en la filosofía- señala que no «trataron nunca de distanciarse demasiado de la tradición, cuyas ilimitadas posibilidades conocían muy bien» (García Jaramillo, 2011: 75). Como concluye Juan Carlos Rodríguez (1999: 288), «[s]í había, pues, una tradición a la que aferrarse y de lo que se trataba era de construir otro edificio a partir de esos ladrillos».

Las estrategias con las que se indaga en la tradición tienen mucho de diálogo «interesado»" como señalaba García Montero, o de lectura «retrospectiva» desde la que enfrentarse al otro discurso

7 Este interés también se vio correspondido por parte de Ángel González cuando escribió algunas líneas sobre Salvador (González, 1996) o Luis García Montero (González, 1998; 2007), a quien llega a citar en un trabajo hablando sobre la influencia delVeintisiete en la poesía joven (1993: 246). Incluso, hay un guiño en su discurso de entrada en la RAE cuando trata sobre la «nueva sentimentalidad» machadiana (1997: 124). Desgraciadamente, el proyectado prólogo de González a una antología de Javier Egea es otra historia (Alcántara, 2010). Por otro lado, el diálogo llegó a concretarse de un modo literal en algunas entrevistas: García Montero (2002), González / García Montero (2007) y Salvador (2009b), donde se recogen las palabras de Ángel González en el ciclo El intelectual y su memoria, durante la estancia en 1990 del poeta en Granada. Rastrear las citas y dedicatorias que se establecen en el diálogo intertextual, las huellas de González sobre algún verso concreto, daría para otro trabajo: no se trataría de señalar, en ese caso, meras «influencias», sino la profunda convicción en un modo de entender la Historia y la poesía. 
a través del discurso propio (Althusser, 1965: 23) ${ }^{8}$. Gil de Biedma, con su habitual perspicacia, recuerda a Auden para desnudar el entramado que se encuentra bajo tales procesos: «Incluso en el mejor de los casos, los poetas metidos a críticos de poesía nunca resultamos del todo convincentes, aunque a veces sí muy estimulantes, precisamente porque estamos hablando en secreto de nosotros mismos» (Gil de Biedma, 1980: 492). Cuando los poetas de la otra sentimentalidad buscan una tradición en la que situarse, la obra de González se convierte en un espejo. Pero la imagen que devuelve tiene que tener rasgos reconocidos para que el mecanismo funcione. Al declarar su deuda con los poetas del Cincuenta, Luis García Montero se refiere a "algo así como la lección de Machado y de Cernuda traída a mi tiempo. Me resultaba fácil identificarla con mis calles, con mi habitación, con mi ventanilla de autobús. Es la lección que se encarna en una verdadera educación sentimental» (González / García Montero, 2007: 40). Los espejos se multiplican.

Para García Montero, los poetas del Cincuenta se agruparon bajo la «bandera generacional» del «conocimiento» — teorizada por Barral frente a la "comunicación»—, insistiendo en que no había verdades previas a la escritura del poema. Situarse en estas coordenadas implica «un nuevo modo de compromiso, una relación dialéctica entre la Historia y el poeta, preocupado ahora en indagar las raíces sociales de su educación sentimental» (García Montero, 1999: 32). Es lógico que el referente de Antonio Machado aparezca de inmediato, puesto que la «síntesis dialéctica» entre identidad e Historia puede considerarse la lección machadiana a la que con más ahínco se aplicó González (Candel Vila, 2002: 197; Iravedra: 2005: 90; Iravedra, 2008: 75). Los poetas de la otra sentimentalidad encuentran en la obra de González y en la de los del Cincuenta

8 Aunque habría que hacer alguna puntualización, pues el "propio discurso" de los poetas de la otra sentimentalidad es inseparable del pensamiento teórico de Juan Carlos Rodríguez, que, a su vez, es deudor del Althusser que detecta en Marx «una nueva práctica de la lectura» y «una nueva teoría del leen» (1965: 23). A la lectura «retrospectiva», seguiría una segunda lectura «sintomática» basada también en dos textos, pero donde el segundo texto se articularía sobre los «lapsus» del primero, sobre sus blancos, sus silencios (ibíd.: 33), lo cual nos lleva de inmediato al terreno de la «ideología», solo visible en sus efectos: de ahí los blancos y silencios. Que el grupo poético granadino lea la obra de Ángel González —construyendo, así, un «objeto» distinto al que ofrecerían otras perspectivas teóricas - desde una concepción del texto entendido como «producción ideológica» y desde su "radical historicidad», con el equipaje teórico que ello conlleva, no impide detectar ese cariz «retrospectivo» de su lectura. 
otro espejo desde el que llegar, de nuevo, a Machado. Para García Montero, la «reivindicación de la intimidad frente al sociologismo» que hace el poeta sevillano, «su respeto de la experiencia histórica frente al individualismo esencialista», ayuda a los poetas del Cincuenta, más allá de la mera influencia, a mantener la conversación más penetrante y matizada que el género poético ha sabido establecer con la intimidad»(1999: 33). Es un diálogo al que no escapa la otra sentimentalidad, interesada en enfrentarse a los sentimientos entendidos como terreno de indagación ideológica. En el magisterio compartido de Antonio Machado, vuelven los poetas granadinos a enlazar con Ángel González ${ }^{9}$, del mismo modo que se alejan de otras líneas poéticas, como la de la literatura social más panfletaria o la de los espectáculos novísimos. En efecto, las lecciones que fundían ética y estética de Machado y González, las preocupaciones compartidas, nada tenían que ver con las supuestas «rupturas» que intentaban los novísimos. Unas rupturas que, en todo caso, se ejecutaban contra «la cultura que intentó oponerse al franquismo», lo que lleva a González a considerar a estos poetas «como la última manifestación de la cultura» de la dictadura (1980b: 387).

García Montero que, desde los planteamientos originarios de la otra sentimentalidad desemboca con coherencia en un "realismo singular» (García, 2002b: 18), coloca a Machado en un lugar preferente en la genealogía que traza:

Con Rafael Alberti de por medio, y con una evidente lectura del pensamiento marxista, otros poetas de la posguerra española seguirían después un camino parecido al abierto por Antonio Machado. Jaime Gil de Biedma, el segundo Carlos Barral y Ángel González, por ejemplo, abordan la poesía como un análisis de la educación sentimental propia elaborado desde la experiencia personal. Será necesario para ellos partir de la realidad y construir una atmósfera

García Montero ha mantenido estos nombres unidos en el tiempo: en un poema de Vista cansada, Ángel González «pone sus pies heridos en la historia» (2008a: 104) al visitar la tumba de Machado. El propio poeta granadino cuenta que González «era el corazón sentimental del grupo» con el que visitó Colliure, «encarnaba la presencia viva de una tradición poética y cívica que me afectaba de un modo muy íntimo» (2009: 52). En el prólogo que escribe Luis García Montero (1999) a los trabajos que González dedicó a Machado, tienen ocasión de juntarse estas tres voces. 
de realidad en sus poemas, pero siempre a través del conocimiento objetivo de su configuración individual. A esta manera de entender las relaciones entre la historia y la individualidad y a sus efectos literarios es a lo que llamaremos [...] el realismo singular (García Montero, 1993d: 19).

La figura de Machado venía ocupando un papel principal ya desde los famosos «manifiestos» de la otra sentimentalidad (Egea et al., 1983). El otro referente indiscutible con el que allí se enlazaba era Jaime Gil de Biedma. Precisamente, en un artículo de Luis García Montero (1982) sobre el poeta, se encuentran los puntos básicos que luego aparecerán en el texto titulado «La otra sentimentalidad» (1983) (García, 2002b: 16). El mismo Gil de Biedma acompañó en el 83 a los poetas granadinos en la presentación de los manifiestos durante los Cursos de Verano en Baeza. La lectura de Gil de Biedma, a la vez que reanudaba los vínculos con la tradición machadiana, abría las puertas a sus compañeros de viaje:

la admiración por la poesía de Gil de Biedma se convirtió muy pronto en admiración por la obra de todos los poetas de la llamada Escuela de Barcelona o Generación del 50, lo que desembocó en el famoso número monográfico que la revista Olvidos de Granada les dedicó en 1986 (Wahnón, 2003: 507) ${ }^{10}$.

Ángel González no aparece citado directamente en los primeros «manifiestos», pero en este horizonte de inquietudes compartidas, no tardaría mucho en aparecer, pasando a formar parte del canon más insobornable de la otra sentimentalidad. Precisamente, García Montero (1997: 68) relata que fue durante la preparación de este monográfico cuando conoció a González. No es casualidad que en diciembre del 85 se celebrase en Granada un homenaje a los poetas del Cincuenta, y que ese mismo año los de Luna de Abajo publicasen en Asturias Guía para un encuentro con Ángel González; en 1986, en la revista Litoral, saldría Jaime Gil de Biedma. El juego de hacer versos, coordinado por Álvaro Salvador, Luis García Montero

10 García Montero ha escrito que «la temperatura del hecho poético es la admiración»: «somos escritores porque antes hemos sido lectores» (2014: 154). Sin embargo, en aquel momento, se permitía un guiño cómplice: «no podemos admirar a Jaime Gil de Biedma. Es demasiada la sombra de su intimidad. A Garcilaso es posible admirarlo. Los poemas de Gil de Biedma se suelen envidiar» (1982: 122). 
y Antonio Jiménez Millán. Era el reconocimiento público de los más jóvenes a una tradición que vivían íntimamente, «una forma de reconocimiento a la tradición cercana con la que más nos identificábamos» (Jiménez Millán, 2003: 191).

La revista Olvidos de Granada, dirigida en su segunda época por Mariano Maresca, «mantuvo muy en vilo el debate cultural contemporáneo, a la altura de una ciudad europea, histórica y universitaria en un país democrático e ilusionado con la transformación que podía proceder de la izquierda» (Soria Olmedo, 2000: 117). Dentro de la variedad de temas por los que se interesaba («cine, filosofia, fotografia, tebeos, urbanismo, enseñanza, novela, jazz, feminismo, música clásica, psicoanálisis, drogas, teatro, ópera»), a nivel literario «la línea más sostenida de Olvidos de Granada fue el interés por la obra de autores del medio siglo» que tuvo su culminación con el número 13 titulado "Palabras para un tiempo de silencio"” (ibíd.: 118). El número tiene mucho valor, porque, aparte de servir como «testimonio amplio y diverso de la vinculación estética y personal del grupo de la otra sentimentalidad» con los autores del Cincuenta, «en particular con Ángel González y Jaime Gil de Biedma» (Díaz de Castro, 2003: 13), encontramos las contribuciones críticas de Jiménez Millán, García Montero y Álvaro Salvador que destacan «por su valor de reflexión metapoética, aplicable a la elección razonada de modelos por parte de estos poetas jóvenes» (Soria Olmedo, 2000: 118).

En unos artículos que, oponiéndose a la estética novísima, se posicionan de parte de los poetas del Cincuenta, será precisamente Álvaro Salvador quien reivindique a «Ángel González y la poética del pudor» (1986). Años más tarde, Salvador (1995: 85) vuelve a este artículo, recordando que para el «inseguro y, en ocasiones, mal informado aprendiz provinciano de poeta», leer en el año 68 Tratado de urbanismo supuso encontrar «un reducto de inesperada solidaridad», ya que «toda la poesía que yo llevaba en mi cabeza, toda la poesía que yo hubiera querido escribir algún día, estaba ya allí, desgranada en los versos de aquel libro prodigioso». Desde ahí y en adelante, Salvador considera a Ángel González como «el "primero" entre los maestros que me acompañan» (ibíd.) ${ }^{11}$. En efecto,

11 En otra ocasión, Salvador matiza las distintas vías de legitimación/indagación que ofrecían la poesía de Gil de Biedma y la de González: «fue especialmente decisivo el magisterio poético de Jaime Gil de Biedma, sobre todo su conciencia 
Ángel González — que escribió uno de sus primeros libros sobre la figura del maestro- se convirtió en un íntimo referente para los poetas de la otra sentimentalidad: una mirada en el espejo. Rastrear sus huellas a través de la intimidad y la Historia puede ser una manera efectiva de acercarnos a su magisterio aunque, obviamente, los matices de su obra den para infinitas lecturas: el paciente vitalismo con el que recorre la ciudad o la memoria del campo de batalla, el modo de mirar las piernas de una muchacha, las canciones que no son solo canciones.

García Montero (2008c: 156) le dedica un «Nocturno» empapado de las noches que seguían a las jornadas de Palabras para un tiempo de silencio. "Cuando un alba rayada / se desploma en la espalda violeta de Granada» no es dificil imaginar a González sacando la poesía — despeinada - a las calles (2009: 321), como también quería Javier Egea (1983: 25). Esa tierna venganza.

crítica tan lúcida y tan inteligente proyectada sobre los mecanismos y la estructura del poema. Jaime fue quizá el maestro vivo que, de un modo más concluyente, me aportó argumentos para la defensa de una poética determinada, aunque Ángel González sería siempre el que me ofrecía unos más abiertos horizontes poéticos, que abarcaban incluso la posibilidad de cierta experimentación prosaica y coloquial muy necesaria para mí y para el desarrollo de mi propia poesía» (Salvador, 2009c: 46). Uno de los aspectos que más interesa a Salvador de González es el que llama «literatura sin literatura» (1995: 86-87): el desprendimiento en los procedimientos estilísticos de toda gratuidad retórica o formalista, que actúa como extrañamiento formal y extrañamiento del espacio canonizado poético. El poema «Eso era amor» - cuyos versos cita en el díptico «Enseñanzas de la edad» (1992) - sirve a Salvador como ejemplo. Explorará esta línea en el artículo «El antipoeta Ángel González» (2009a), señalando puntos comunes con la obra de Nicanor Parra. No extraña esta indagación crítica por parte de Salvador, que ya había iniciado con un temprano libro (1975) sobre el poeta chileno y que continúa con la reivindicación de ciertos procedimientos vanguardistas (1994: 219). 


\section{BIBLIOGRAFÍA}

Alcántara, José Luis (2010). «Homenaje a Javier Egea (Historia de una antología)", Revista de Crítica Literaria Marxista, 3, pp. 90-93.

Althusser, Louis (1965). «De El Capital a la filosofia de Marx», en Louis Althusser y Étienne Balibar, Para leer El Capital, México, Siglo xxı, 1969, pp. 18-77.

Bagué Quílez, Luis (2005). «Las huellas de una complicidad:Ángel González y la última poesía española», Zurgai [monográfico Con Ángel González], pp. 110-116.

— (2014). «"No acaba aquí la historia”: Ángel González en la poesía española actual», Prosemas, 1, pp. 241-264.

Benjamin, Walter (2008). Obras. Libro I / vol. 2, Madrid, Abada.

Candel Vila, Xelo (2002). «Ángel González y su diálogo con el discurso dialéctico de Antonio Machado», Litoral, 233 [monográfico Ángel González. Tiempo inseguro], pp. 194-201.

Cano Ballesta Juan (1996). La poesía española entre pureza y revolución (1920-1936), Madrid, Siglo Veintiuno.

Díaz de Castro, Francisco (2003). La otra sentimentalidad. Estudio y antología, Sevilla, Fundación José Manuel Lara.

Egea, Javier, Salvador, Álvaro y García Montero, Luis (1983).

La otra sentimentalidad, Don Quijote, Granada.

GARCíA, Miguel Ángel (2002a). «Marxismo y literatura. Sobre los modos de producción teórica», Elvira, 4, pp. 31-45.

- (2002b). «Literatura e historia en la otra sentimentalidad (o cómo poner a la poesía en un compromiso)", Ínsula, 671-672 [monográfico Los compromisos de la poesía], pp. 16-18.

- (2006). «Y casi por compromiso. Consideraciones sobre poesía actual y política», Paraíso, 1, pp. 25-35.

- (2012). La literatura y sus demonios. Leer la poesía social, Madrid, Castalia.

- (2014). «Todas las mansiones de la poesía. El Veintisiete en la crítica literaria de Ángel González», Prosemas, 1, pp. 213-239.

García Jaramillo, Jairo (2011). La poesía de Javier Egea, Granada, Zumaya.

García Montero, Luis (1982). «Impresión de Jaime Gil de Biedma», en García Montero (1993b), pp. 119-122.

— (1983). «La otra sentimentalidad», en Egea, Salvador y García Montero (1983), pp. 9-15. 
- (1986). «Del cincuenta en adelante», Olvidos de Granada, 13 [monográfico Palabras para un tiempo de silencio. La poesía y la novela de la generación del 50], pp. 147-149.

- (I987). «Un tiempo para la ternura (Benedetti, Cardenal y

Dalton)», en García Montero (1993c), pp. 193-207.

— (1992). «¿Por qué no sirve para nada la poesía? (Observaciones en defensa de una poesía para los seres normales)", en Luis García Montero y Antonio Muñoz

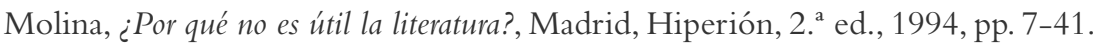

- (1993a). «Trazado de fronteras», en Poesía (1980-

2005), Barcelona, Tusquets, 2006, pp. 551-562.

- (1993b). Confesiones poéticas, Granada, Diputación de Granada.

- (1993c). El realismo singular, Bilbao, Instituto Vasco de las Artes y las Letras.

— (1993d). «El realismo singular», en García Montero (1993c), pp. 7-24.

- (1993e). «Historia y experiencia en la poesía de Ángel

González», en García Montero (1993c), pp. 93-120.

— (1997). «Otra copa más con Ángel González», en Guía para un encuentro con Ángel González, Oviedo, Luna de Abajo / Tribuna Ciudadana, 3. a ed. aum., pp. 68-69.

- (1999). «Soledades y palabras (Sobre Antonio Machado y Ángel González)», en Ángel González, Antonio Machado, Madrid, Alfaguara, pp. 15-40.

— (2002). «Conversación con Ángel González», Litoral, 233

[monográfico Ángel González. Tiempo inseguro], pp. 16-25.

— (2007). «El pudor de Ángel», Cuadernos Hispanoamericanos, 680, 31-34.

- (2008a). Vista cansada, Madrid,Visor, 2. ${ }^{\text {a }}$ ed.

— (2008b). "Ángel, me dicen. Sobre la utilidad de las palabras»,

Cuadernos Hispanoamericanos. Los Complementarios, 17, pp. 22-36.

- (2008c). «La historia leída», Inquietudes bárbaras, Barcelona, Anagrama, pp. 131-157.

- (2009). «En la tumba de Antonio Machado», Ínsula, 745-

746 [monográfico Colliure, 1959], pp. 50-51.

- (2014). Un velero bergantín. Defensa de la literatura, Madrid,Visor.

Gil de Biedma, Jaime (1980). «Nota preliminar», Poesía y prosa, ed. James Valender,

Barcelona, Círculo de Lectores / Galaxia Gutenberg, 2010, pp. 491-494.

GonZÁlez, Ángel (1963). «Poesía y compromiso», en González (2005), pp. 450-452.

— (1965). «Defensa de la poesía social», en González (2005), pp. 453-454. 
— (1968). «Respuesta a un cuestionario», en González (2005), pp. 455-457.

— (1977). «La obra poética de Gabriel Celaya», en González (2005), pp. 287-311.

— (1980a). «Las intenciones y la situación», en González (2005), pp. 403-416.

- (1980b). «Poesía española contemporánea», en González (2005), pp. 379-389.

— (1981). «El primer Juan Ramón en su contexto», en González (2005), pp. 135-156.

— (1984). «Sobre poesía y poetas», en González (2005), pp. 458-459.

- (1987). «La intertextualidad en la obra de Blas de

Otero», en González (2005), pp. 266-286.

- (1990). «Autopercepción intelectual de un proceso

histórico», en González (2005), pp. 417-449.

— (1991). «El exilio en España y desde España», en González (2005), pp. 249-265.

— (1993). «La poesía de la generación del 27», en González (2005), pp. 228-246.

— (1996). «La poesía de Álvaro Salvador», en González (2005), pp. 388-393.

— (I997). «Las otras soledades de Antonio Machado», en González (2005), pp. 101-134.

- (1998). «Completamente viernes: el amor entretanto y

entre todo», en González (2005), pp. 394-400.

— (2002). «Sobre la poesía: un alegato», en González (2005), pp. 477-484.

- (2005). La poesía y sus circunstancias, ed. José Luis García Martín, Barcelona, Seix Barral.

- (2007). «Luis García Montero», Cuadernos Hispanoamericanos, 680, pp. 43-45.

- (2009). Palabra sobre palabra. Obra completa (1956-2001), Barcelona, Seix Barral.

González, Ángel y García Montero, Luis (2007). «Cuestión de palabras», Cuadernos Hispanoamericanos, 680, pp. 35-41.

Iravedra, Araceli (2005). «Entre las voces, una. Procedimientos machadianos de Ángel González», Zurgai [monográfico Con Ángel González], pp. 86-96.

- (2008). «Ángel González y el pleito de la poesía», Cuadernos

Hispanoamericanos. Los Complementarios, 17, pp. 68-83.

- (2010). El compromiso después del compromiso. Poesía, democracia y globalización (Poéticas 1980-2005), Madrid, Universidad Nacional de Educación a Distancia.

Jiménez Millán, Antonio (1986). «La poesía de un tiempo», Olvidos de Granada, 13 [monográfico Palabras para un tiempo de silencio. La poesía y la novela de la generación del 50], pp. 146-147. 
- (2002). «Ángel González: Crónicas y notas de un viajero», Litoral, 233 [monográfico Ángel González. Tiempo inseguro], pp. 240-243.

— (2003). «Complicidades: Luis García Montero», en Jiménez Millán (2006), pp. 187-201.

— (2005). «Poéticas para un fin de siglo», en Jiménez Millán (2006), pp. 21-124.

- (2006). Poesía hispánica peninsular [1980-2005], Sevilla, Renacimiento.

Mora, Ángeles (1990). La dama errante, Granada, Caja General de Ahorros y Monte de Piedad de Granada.

- (2001). Contradicciones, pájaros, Madrid,Visor.

- (2006). «El desafio cotidiano o la poesía de Ángel González», en Ángel

González, un clásico de nuestro tiempo, eds. José Guerrero, Elena Peregrina y

Álvaro Salvador, Almería, Universidad de Almería, pp. 199-111

Prado, Benjamín (2008). «Ángel González, la coherencia en sílabas contadas», Cuadernos Hispanoamericanos. Los Complementarios, 17, pp. 56-60.

Rodríguez, Juan Carlos (1998). «Brecht y el poder de la literatura», en Brecht, siglo xx, ed. Juan Carlos Rodríguez, Granada, Comares, pp. 15-207.

- (1999). Dichos y escritos. (Sobre "la otra sentimentalidad" y otros textos fechados de poética), Madrid, Hiperión.

Salvador, Álvaro (1975). Para una lectura de Nicanor Parra (El proyecto ideológico y el inconsciente), Sevilla, Secretariado de Publicaciones de la Universidad de Sevilla.

- (1983). «De la nueva sentimentalidad a la otra sentimentalidad», en Egea, Salvador y García Montero (1983), pp. 17-23.

- (1986). "Ángel González y la poética del pudor», en Las rosas artificiales. (La búsqueda de la modernidad en la poesía hispánica), Sevilla, Fundación Genesian, 2003, pp. 257-270.

- (1992). La condición del personaje, Granada, Caja General de

Ahorros de Granada y Monte de Piedad de Granada.

- (1994). «Con la pasión que da el conocimiento: notas acerca de la llamada otra sentimentalidad», en Salvador (2003), pp. 209-220.

— (1995). «La palabra precisa de Ángel González», en Salvador (2003), pp. 85-94.

- (2003). Letra pequeña, Granada, Cuadernos del Vigía.

— (2009a). «El antipoeta Ángel González», Campo de Agramante, 12, pp. 85-101.

- (2009b). El intelectual y su memoria. Ángel González

[entrevista], Granada, Universidad de Granada. 
- (2009c). «Un lugar para la literatura española», Ínsula, 745-

746 [monográfico Colliure, 1959], pp. 45-46.

Soria Olmedo, Andrés (2000). Literatura en Granada (1898-

1998). II Poesía, Granada, Diputación de Granada.

WaHNón, Sultana (2003). «Lírica y ficción: de la otra sentimentalidad a la poesía de la experiencia», en Homenaje a la profesora María Dolores Tortosa Linde, ed.

Remedios Morales, Granada, Universidad de Granada, pp. 493-510. 